\title{
Reflexiones durante la devastación: el despligue del Coronaceno en Chile ${ }^{1}$
}

\author{
Reflexões durante a devastação: 0 \\ desenvolvimento do Coronaceno no Chile
}

\author{
Wladimir Riquelme Maulén*1 \\ Ricardo Álvarez Abel $* * 1$ \\ Camila Bañales-Seguel $* * * 1$ \\ Francisco Araos Leiva $* * * * 1$ \\ Amapola Núñez Marengo*****1
}

\section{Palabras claves: Coronaceno; Devastación;} Regeneración de la vida; Chile.

\begin{abstract}
Resumen: La devastación de la vida en tiempos del Covid-19 o Coronaceno está antecedida por un conjunto de catástrofes, tragedias y calamidades que, desde Chile, requieren una reflexión antropológica para analizar su despliegue. La crisis ambiental a escala global ha deteriorado el devenir de la vida en los territorios y la manifestación local de la pandemia da cuenta de ello. En el presente artículo analizamos a la devastación en su dimensión territorial, para así reflexionar sobre el despliegue del Coronaceno en Chile en que se visibilizan siniestros normativos y futuros posibles que emergen de las decisiones comunitarias para amortiguar las consecuencias de la pandemia del Covid-19 en sus territorios. La devastación da cuenta de un escenario de catástrofe que ha sido provocado conscientemente y asumiendo las consecuencias. Por tanto, proponemos que la devastación es resultado decisional de la acción humana a sabiendas de que deteriora casi irreversiblemente las condiciones de vida, incluso
\end{abstract}

\footnotetext{
${ }^{1}$ Recebido em 20/09/2020. Aceito em 02/06/2021.

*1 Magíster en Asentamientos Humanos y Medio Ambiente y Antropólogo. Grupo de Antropología de la Conservación, Universidad de Los Lagos. E-mail: wladiriquelme@gmail.com.

${ }^{* * 1}$ Estudiante de Doctorado de Ciencias Sociales en Estudios Territoriales y Antropólogo. Universidad de Los Lagos.

***1 $\mathrm{Ph}(\mathrm{C})$ Ciencias Ambientales e Ingeniera Agrónoma. Facultad de Ciencias Ambientales, Universidad de Concepción.

$* * * *^{1}$ Doctor en Ambiente y Sociedad y Antropólogo. Universidad de Los Lagos. E-mail: francisco.araos@ulagos.cl

$* * * * * 1$ Licenciada en Geografía. Universidad Alberto Hurtado.
} 
Keywords:

Coronacene;

Devastation;

Regeneration of life;

Chile. aquellas que permiten revertir la situación. El despliegue del Coronaceno en Chile es fecundo para aproximarnos a estas reflexiones durante la devastación.

Abstract: The devastation of life in times of Covid-19 or Coronacene is preceded by a set of catastrophes, tragedies and calamities that require anthropological reflection to be analyzed from Chile. The global environmental crisis has deteriorated the future of life in the territories and the local manifestation of this pandemic accounts for it. In this article we analyze the devastation in territorial dimension, in order to reflect on the unfolding of the Coronacene in Chile in which regulatory and possible future losses emerge from community decisions that cushion the consequences of the Covid-19 pandemic in their territories. The devastation accounts for a catastrophic scenario that has been consciously caused and assuming its consequences. Therefore, devastation is the decisive result of human action, and it almost irreversibly deteriorates living conditions, even those that allow the situation to be reversed. The unfolding of the Coronacene in Chile is fruitful approach to these reflections during the devastation.

\section{Introducción}

$\mathrm{P}$ or la mañana del día 21 de mayo del año 2021 se reunieron vecinas y vecinos del Barrio Lastarrias, en el corazón de Santiago (capital de Chile) para distribuir alimentos a las ollas comunes en las poblaciones de El Bosque, Lo Hermida, Santa Julia y Juan Antonio Ríos, retomando una práctica de solidaridad y preocupación comunitaria que yacía postergada en la memoria colectiva sobre tiempos en los que la pobreza era extendida a buena parte de la población y era un fenómeno cotidiano. La profunda crisis económica que acontece en tiempos de la pandemia del Covid-19 se manifiesta en la visibilidad pública del hambre, paradójicamente cuando el país exhibe indecorosamente el enriquecimiento constante de algunas familias cuyo patrimonio se promociona en competencias globales sobre quién es más rico.

El Covid-19 también impactó a zonas lejanas, que se suponía protegidas por su aislamiento: en Alto Biobío, a 658 kilómetros al sur de Santiago, se conoció el primer caso. Siete días después la cifra llegó a 36 personas, teniendo como foco de contagio una empresa de frutas que trabajó sin resguardos sanitarios. En este territorio, hábitat ancestral de familias y comunidades Pewenche, se decidió instalar un cordón sanitario gestionado por las propias comunidades locales para controlar los flujos de personas que provocaron la crisis. El jueves 21 de mayo, feriado chileno por las "Glorias Navales", quedó en la memoria de ambos territorios como una vivencia de hambre, pero sobre todo, constató la precaria condición de autonomía en territorios indígenas,

Caderno Eletrônico de Ciências Sociais, Vitória, v. 8, n. 2, pp. 70-83, 2021. 
impidiéndoles desenvolverse autónomamente en base a sus propios funcionamientos para enfrentar la pandemia del Covid-19, la que adquirió, como en muchas otras partes del país, el carácter de devastación.

La crisis ambiental a escala global ha deteriorado el devenir de la vida en los territorios (LEFF, 2019), y las otras devastaciones en tiempos de la pandemia del Covid-19 o Coronaceno (SKEWES; ARAOS; RIQUELME, 2020) da cuenta de ello. La temprana premisa de la tragedia de los comunes (HARDIN, 1968) se ha ampliado exponencialmente al común de las tragedias (ABALERON, 2010) que compartimos cotidianamente a escala global. Con ello, "la autonomía de los procesos locales en términos de las definiciones que le son propias para su comprensión de los procesos vitales resultantes de micro-políticas abiertas a coaliciones heterogéneas en su composición, incluyendo a seres más que humanos" (ARAOS et al., 2019, p. 5). En palabras de Anna Tsing (2015), vivimos en paisajes de ruinas de un modelo de vida que lo devastó todo. Etimológicamente, la devastación (vastatio) da cuenta de un escenario de catástrofe (todo se viene abajo) consciente o inconscientemente provocado por decisiones de personas, instituciones y/o grupos de personas, cuya afectación está en otros o más bien asumen sus consecuencias. 
Figura 1: Mapa de lugares mencionados en la reflexión.

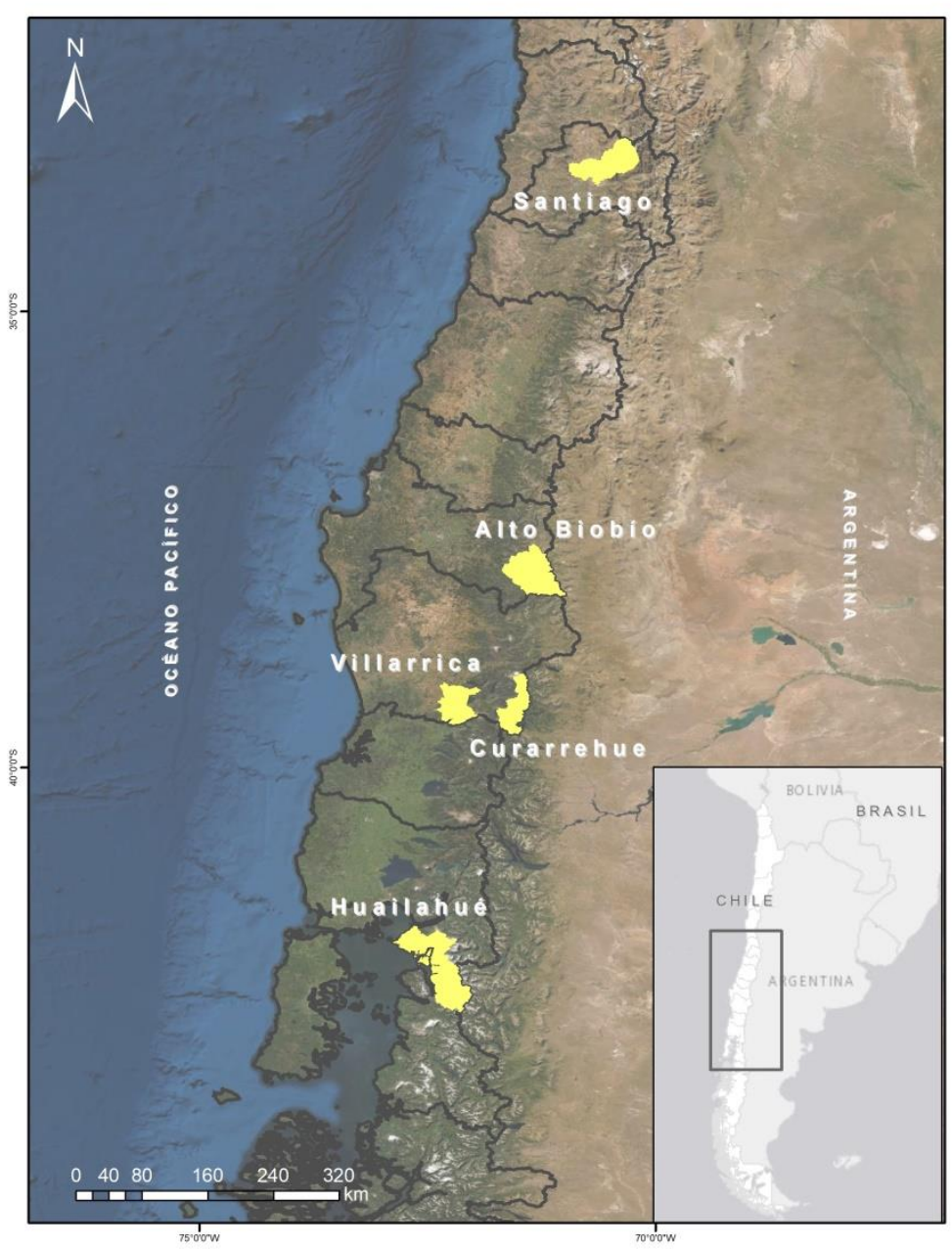

Elaboración: Amapola Núñez.

"Hasta en las desgracias hacen negocios" es una expresión popular que sintetiza un conjunto de decisiones gubernamentales a mediados de marzo y que se manifiestan que entre junio y julio entran en cuarentena las comunas de Arica, Calama, Antofagasta, San Antonio, Rancagua y Puerto Montt: ciudades cuyo eje industrial requiere de la movilidad de sus trabajadores. Esto es una constatación de que se privilegió el desarrollo económico en desmedro de razones sanitarias. Es una devastación en que se asumen sus consecuencias, pero las vivencian otras personas, en otros asentamientos humanos, en otros territorios. De este modo, la devastación es resultado decisional de la acción humana a sabiendas de que deteriora casi irreversiblemente las condiciones de vida. El resultado es la experiencia vivida, el desastre (pérdida de referentes predecibles de la vida), cuya ruina (hundirse) se territorializa en la crisis, experiencia y devenir de la devastación en tiempos del Coronaceno. 


\section{Tiempos del Coronaceno}

El Coronavirus surgió, al menos oficialmente, a finales del año 2019 en la ciudad de Wuhan en China. Tal y como ocurrió con otros virus en años anteriores, el nuevo coronavirus se extendió rápidamente por las ciudades del centro del país, aunque a diferencia de aquellas, esta vez el virus traspasó las fronteras nacionales y continentales, transformándose en una pandemia global.

El Covid-19 se genera a partir de una zoonosis, una patológica relación entre humanos y animales (BONILLA-ALDANA et al. 2020; TANG et al. 2020). Esta relación no es una excepción en el último tiempo ya que hemos vivido de una creciente cantidad de emergencias epidemiológicas en el planeta surgidas por zoonosis: zika, grive aviar, gripe porcina, ébola, entre otras. Este contexto epidemiológico da cuenta de una época en que el ser humano se ha transformado en el principal agente modelador de las dinámicas en el planeta, que nos remite al Antropoceno (Araos et al. en prensa).

Acompañando la discusión antropológica acerca del Antropoceno (HARAWAY et al., 2016; TSING, 2017), reconocemos en el tiempo del coronavirus un momento de emergencia, de crisis ambiental y restauración de la justicia social (Araos et al. en prensa). Asi, frente al escenario de devastación causado por la pandemia, el Coronaceno emerge como un tiempo de experimentación y ensayo para sortear la crisis civilizatoria producida por el 'hombre' en su asociatividad con los virus, trazando un nuevo paisaje donde la convivencia entre múltiples seres - incluidos virus, animales y humanos - sea el principio para la resurgencia de la vida (SKEWES, 2019). El Coronaceno, por lo tanto, representa un momento paradójico de la historia, de cierre de fronteras geográficas y culturales- pero también de apertura a nuevos arreglos sociambientales y políticos. Un momento histórico que se transforma en vivencia en la medida en que se reconocen las causas de la crisis y se ensayan salidas para un futuro después de la devastación.

\section{Apertura: Siniestros Normativos}

Las causalidades de la devastación han sido profundamente estudiadas (ANGUS, 2016; CRUTZEN Y STROERMER, 2000; FLEMING, 2017; HARAWAY et al., 2016) como parte de procesos globales ligados a los cambios ambientales del modelo de desarrollo actual. Pero, resulta interesante reflexionar sobre algunos aspectos particulares de su detonación: ¿quiénes son los agentes que activan la devastación?, ¿son los cuadros político-administrativos que sirven como operadores del modelo a escala territorial?, ¿son la mano de obra que lo implementa de manera práctica pues no tienen otra posibilidad de adquirir un salario - como los millares de seres humanos que talan la selva o depredan el

Caderno Eletrônico de Ciências Sociais, Vitória, v. 8, n. 2, pp. 70-83, 2020. 
mar a bordo de busques pesqueros-? O bien, ¿son los cuadros normativos que permiten esta devastación?, lo que implicaría redefinir a los siniestros (sinister, acción que resulta negativa, desfavorable) desde su mera manifestación socioambiental a una precursora como "siniestro normativo" (ÁLVAREZ et al., 2019; ARAOS et al., 2019). O también, reflexionar sobre la devastación considerando los futuros de mundos posibles que se activan desde ese momento (TSING, 2017; BALANDIER, 2003), incluyendo la posibilidad de regeneración de la vida (SKEWES, 2019; ARAOS et al. 2019; HARAWAY, 2016). Pero también resulta interesante preguntarse sobre la devastación y un mundo sin humanos (WEISMAN, 2007). La integración de estas variables emergentes se puede dilucidar en la dimensión territorial de la devastación.

La devastación en tiempos antiguos tenía que ver con decisiones estratégicas de dominio. Por ejemplo, las incursiones romanas en territorio galo generaban actos de ruina para impedir las posibilidades de vida y resistencia entre sí. De esta forma, tanto romanos como galos eliminaban todo lo que pudiese servir al otro para sostenerse. Esto implicaba no sólo quemar poblados y plantaciones, o acabar con el ganado, sino incluso talar los bosques para que no fuese posible reconstruir lo dañado. Esta receta fue implementada recurrentemente a lo largo del tiempo, por lo que no es de sorprender que en la conquista de América fuese una conducta recurrente e institucionalizada a escala regional. Por ejemplo, la crónica de Hernán Cortés vuelva en ello cuando relata cómo conquistaron México a principios del siglo XVI, y lo mismo hicieron otros conquistadores a medida que avanzaban hacia el sur. Por cierto, desde los pueblos originarios que eran atacados se desplegaba algo similar, evitando con ello que la amenaza hispana se robustece. Durante la 'pacificación' de la Araucanía el ejército chileno se encargó -además de perpetrar masacres- de destruir siembras y ganado con el propósito de que los sobrevivientes no pudiesen reagruparse y recuperar fuerzas, pero, sobre todo, no tuviesen posibilidad alguna de volver a habitar los lugares que fueron devastados (BENGOA, 2000).

Nos preguntamos si esta forma de devastación -como acto intencionadotambién opera hoy en día a escala de industrias extractivas que operan bajo cuadros normativos estatales. Por cierto, preliminarmente no se esperaría que uno de los objetivos de su implementación sea destruir lo preexistente. Sin embargo, por lo visto es parte de los mecanismos no explícitos para alcanzar un grado de eficiencia ad hoc con las intenciones de generación de lucro. Cuando este fenómeno ocurre legítimamente, bajo el alero de decisiones normadas (ÁLVAREZ et al., 2019), apelamos al término de 'siniestro normativo', "(...) entendido como la imposición de sistemas de normas sobre los bienes comunes que detonan transformaciones profundas en los sistemas locales, que afectan tanto a las poblaciones humanas como al ecosistema" (ARAOS et al., 2019, p.

Caderno Eletrônico de Ciências Sociais, Vitória, v. 8, n. 2, pp. 70-83, 2021. 
89). Por cierto, ocurre a diferentes escalas. Por ejemplo, la expansión de cultivos transgénicos sucede por medio del reemplazo de especies vegetales locales, tanto cultivables como no cultivables, así como micro-fauna acompañante, para lo que se utilizan plaguicidas y herbicidas que provocan externalidades más allá del radio en el que se implementa esta estrategia. Para ello, grandes industrias influyen en las políticas de Estados para que sus procedimientos, así como la inclusión de sus productos químicos y semillas patentadas, sean legítimas e idealmente la única opción disponible en el comercio. El problema surge cuando, en sentido contrario, otras especies reafectan lo transformado (espacios, procedimientos, economías, etc.) y generan respuestas inesperadas que anulan el funcionamiento de estos cultivos, desencadenando una suerte de caos que agudiza aún más el problema. Este es el caso, por ejemplo, de amarantos ${ }^{2}$ afectados genéticamente por transgénicos cultivados en Estados Unidos. Lo que ocurrió con este fenómeno es que estas plantas se volvieron resistentes a los herbicidas y colapsaron el cultivo de algodón en más de 70 estados, siendo catalogada como una 'súper maleza' que impide tanto la agricultura industrial como cualquier otra forma de cultivo. La devastación de ecosistemas y sistemas agroalimentarios tradicionales se vuelve bajo esta lógica una institución, ya que lo reglamentado estructura las interacciones socioecológicas que allí deberán ocurrir.

Las extensas plantaciones de pinos y eucaliptus en Chile están asociadas al Decreto Ley 701 creado durante la dictadura militar y que fomenta el reemplazo de bosque nativo por plantaciones exóticas. Operan bajo la lógica de reemplazo de uso de suelo agrícola o bosque nativo (mediante tala rasa de bosques preexistentes) y, por supuesto, implica el desplazamiento de grupos humanos que vivían en dichos lugares, siendo especialmente conocido el impacto sobre el pueblo mapuche. El problema que provoca este tipo de cultivos, altamente densos y próximos a espacios poblados, es que son frecuentemente afectados por incendios que adquieren connotaciones dantescas por el hecho de que 'cercan', o rodean a la población, sus asentamientos y caminos, generando una destrucción que se instala de manera crónica en dichos espacios. La incertidumbre y temor que provoca esta situación puede percibirse en el relato de un habitante de Santa Bárbara, en la región del Biobío: "(...) ni dios quiera parezca un incendio, cómo lo vamos a apagar acá, no tenemos salvación" (FSP, 2016, p. 37). A ello debe sumarse los problemas derivados de la disminución de disponibilidad de agua provocadas por estas especies sobre el entorno, la pérdida de biodiversidad, deterioro de infraestructura vial a causa de transporte constante de camiones, pérdida de oficios locales como la apicultura, desempleo y pobreza, etc. Por ello se asume que muchos de estos incendios

\footnotetext{
${ }^{2}$ Amaranthus, llamado 'kiwicha' en el mundo andino desde donde proviene originalmente.
} 
fueron actos intencionados, buscando provocar la destrucción de esta industria que, finalmente, afecta a todos quienes la rodean. Es por ello que las extensas plantaciones forestales ligadas a esta industria son un siniestro normado que provoca devastación, pues es imposible co-habitar con ellas y es imposible no salir perjudicado. No por casualidad es percibida como el avance de un 'desierto' verde pues "(...) puede que no cambie el color del paisaje, pero sí todo lo que se abriga en él" (Op cit., p. 25).

Otro caso que resulta interesante de exponer tiene relación con la Ley de Pesca y Acuicultura ( $\left.\mathrm{N}^{\circ} 18.892\right)$. Su promulgación en la década de los ' 90 vino a contrarrestar la liberalización normativa que había tenido lugar durante la dictadura, y que provocó una pérdida de biomasa sin parangón en manos de industrias extractivas, además de transformaciones demográficas y culturales a gran escala en este entorno, entre muchas otras externalidades. Pues bien, esta norma impuso reglas para el uso de especies hidrobiológicas y el espacio marítimo que restringieron las prácticas pesquero-artesanales y facilitaron la expansión de la industria acuícola (representada por la mitilicultura, pero por sobre todo por la cría de salmones). Los impactos de esta última sobre los espacios marinos son innumerables: captura de áreas para emplazar las balsas jaulas que tradicionalmente eran utilizadas para la pesca (a través de la figura normada de concesión acuícola); acumulación de enormes volúmenes de fecas bajo dichas áreas que generan ambientes anóxidos y florecimientos algales; vertido de otros desechos (plásticos, metálicos, etc.) que por su materialidad pueden desplazarse y contaminar zonas alejadas de la concesión en sí; trastornos laborales recurrentes (como eventos de desempleo masivo que desencadenan situaciones de pobreza multidimensional y migraciones oscilatorias); afectación de fauna nativa por efecto de plaguicidas y antibióticos, pero también por su transformación en harina de pescado para la confección de alimento para salmones, etc. (MARCEL; OPORTO, 2000; GARCÍA, 2005; SEPÚLVEDA et al. 2013; FUNDACIÓN TERRAM, 2018). Con resultado inesperado surge la eutrofización del mar como escenario de devastación ya que, entre sus muchas manifestaciones están eventos de floraciones algales nocivas (BUSCHMANN, 2005) con graves daños económicos para su producción industrial, pero también para todos quienes co-habitan estas aguas, tanto humanos (y sus economías, asentamientos, patrones culturales, etc.) y no humanos.

La palabra 'desierto' expuesta en el caso forestal es lo que intencionadamente deseaban provocar quienes buscaban la devastación en tiempos antiguos. Esto es, la imposibilidad de que tanto unos como otros pudiesen habitar. La industria forestal en su afán de crecimiento y lucro provoca finalmente la destrucción de sí misma y de quienes la rodean, impidiendo las posibilidades de resurgir de las cenizas. La salmonicultura, también en su afán

Caderno Eletrônico de Ciências Sociais, Vitória, v. 8, n. 2, pp. 70-83, 2021. 
de crecimiento y lucro, colapsa los servicios ecosistémicos de los canales y fiordos chilenos al grado de provocar su eutrofización. Con ello, ni la salmonicultura, ni ninguna otra forma de explotación o uso del mar puede ocurrir ya que las aguas coloquialmente se han 'podrido'. Finalmente, la ambición exportadora por poseer agua en desmedro de miles de familias de agricultores en el secano costero, y de ecosistemas frágiles que allí resisten, lleva a la devastación de todos sin posibilidades de recuperación. Por ello, la devastación opera como mecanismo de anulación de la vida de forma deliberada y normada, por tanto, siniestro normativo abalado y blindado por el Estado.

\section{Vivencia: acontecimientos territoriales}

La comprensión del territorio como acontecimientos que fluyen y dotan de significado a cada colectividad (THER, 2012) permite profundizar en una apertura en la dimensión territorial de la devastación. En los acontecimientos se dan cuenta de los diversos procesos de cambios y transformaciones que acontecen y manifiestan las múltiples relaciones que construyen social, espacial y temporalmente a los territorios. Los cordones sanitarios mapuche son constatación de ello. El medio de comunicación mapuche "Mapuexpress" diseñó (en colaboración con CIGIDEN) un mapa del desenvolvimiento del Coronavirus en Wallmapu - territorio mapuche -; ver en: https://covid-in-wallmapu.github.io. Es un mapa virtual colaborativo, en que personas suministran información y permiten construir colectivamente una base de datos sobre la situación. Las categorías para subir información son "control territorial", "defensa territorial", "soberanía alimentaria", "patrimonio sanitario ancestral", "violencia política", "necesidades y solidaridad territorial (Trafkintu)" y "avance extractivista". En cuanto a la dimensión territorial, las categorías sobre control territorial se definen como acciones y declaraciones de comunidades que refuerzan 0 debilitan el control territorial político, económico, sanitario o cultural. Incluyen las barreras sanitarias y declaraciones públicas, las cuales se concentran en los sectores cordilleranos de Alto Biobío, Coñaripe y Panguipulli y en el sector costero de Lago Budi. En cuando al avance extractivista, este se concentra en sectores del valle de La Araucanía, la costa de Valdivia y en el mar interior de Hornopirén. Los dos primeros coinciden con los proyectos aprobados en el Servicio de Evaluación Ambiental entre mayo y julio y el último al escape de salmones en la playa de Isla Llanchid a mediados de junio.

Lo anteriormente descrito da cuenta de construcciones sociales, espaciales y temporales que permiten visualizar la comprensión de los territorios como acontecimientos. A su vez, las diversas categorías para colaborar en el mapa dan cuenta de la diversidad de imaginarios territoriales que acontecen en Wallmapu, en cuanto al cuestionamiento de la modernidad y

Caderno Eletrônico de Ciências Sociais, Vitória, v. 8, n. 2, pp. 70-83, 2020. 
expresiones identitarias (ALIAGA; CARRETERO, 2016), miradas críticas al desarrollo (CASTORIADIS, 2005) y al reconocimiento de cómo las comunidades locales se relacionan con sus territorios. Se territorializan imaginarios políticos y que son parte de los profundos procesos de autodeterminación cultural y territorial mapuche que se vivencian en tiempos contemporáneos (MARIMÁN, 2012).

Hasta abril 2021, la comuna de Alto Biobío no padecía el acontecimiento de la tercera ola de contagios del país. Esta fuerte ola fue resultado del aflojamiento de restricciones sanitarias durante el verano en la forma de asignación de "permisos para vacaciones" que permitieron el movimiento interregional de miles de familias y una falsa sensación de seguridad por el extenso despliegue del programa de vacunación. El desarrollo de la tercera ola de contagios llamó la atención a nivel internacional por contrastar con lo esperado de un país que ha demostrado tener un programa de vacunación ejemplar a nivel mundial. Entre las comunas más afectadas por la tercera ola fueron aquellas con fuerte afluencia de turismo (Villarrica, Pucón y Panguipulli), que rápidamente fueron sometidas a cuarentena luego del fin del verano y el incremento acelerado de contagios. Alto Biobío fue una excepción, pese a recibir gran afluencia de turistas visitantes, los contagios no se dispararon cómo en otras partes.

No fue hasta fines de abril cuando un nuevo brote que llevó a la comuna a cuarentena. Este brote no fue causado tanto por forzantes externos como internos. El incremento de los contagios se debió a una combinación de dos procesos. Por una parte, a fines de marzo y durante abril, cada una de las 12 comunidades Pewenche de la comuna celebró su respectivo gillatun ceremonia central en la cultura Mapuche - que, en este territorio, se celebra al inicio del verano para pedir por buenas cosechas y al finalizar el verano para agradecer y pedir un buen paso por el invierno. Estas ceremonias agrupan a todas las familias de la comunidad y reciben invitados de otras comunidades, son prácticas culturales inalienables el compartir la comida, el mate y la conversa en torno al fuego. Bastaba que un solo familiar o visita estuviera contagiada para que todos quienes compartieran mate fuesen expuestos a un posible contagio. El segundo proceso que facilitó el esparcimiento de virus, fue el despliegue territorial de campañas políticas, en particular la campaña del alcalde actual impulsada por funcionarios de la propia municipalidad. A pocas semanas de las elecciones municipales, los candidatos realizan caravanas de campaña en las que visitas las distantes comunidades en los sectores rurales y aislados de la comuna, algunos hasta tres horas desde el pueblo de Ralco, capital comunal. En estas caravanas, los funcionarios municipales y sus familiares realizan visitas a los habitantes de las comunidades en las que intentan asegurar votos para la elección. Se comparte comida, mate y la

Caderno Eletrônico de Ciências Sociais, Vitória, v. 8, n. 2, pp. 70-83, 2021. 
inevitable cercanía cultural. Estos dos procesos generaron, dentro de un lapso de 1 semana, a un aumento de casos desde 0 a más de 160. Ambos procesos se atraviesan por un descuido generalizado y falta de cumplimiento de medidas sanitarias básicas (uso de mascarillas, distanciamiento físico) resultante de una ausencia prolongada del virus en el territorio. En efecto, desde Mayo del 2020, la comuna casi no había presentado casos, parecía un "paraíso pandémico", lo que llevó a un relajo de los habitantes, incluso a una porfía expresada por varios como incredulidad de que el virus si quiera existiera. Fue común escuchar frases como "el virus winka - extranjeros - no afecta a los pewenches", "el virus no llega para acá", "para mi que la pandemia no existe".

Este brote contrasta con el brote de Mayo 2020, en dónde los contagios ocurrieron en un espacio laboral externo a la comuna (empresa frutícola que empleaba a muchos habitantes de Alto Biobío). En aquella ocasión, las personas fueron rápidas para expresar enojo con la empresa y exigir indemnización por gastos médicos. En este caso los habitantes se vieron enfrentados entre ellos y se exacerbaron divisiones propias de una comuna con profundas raíces de división política y cultural. Todos buscaron a quien apuntar el dedo: quienes asistieron a gillatun culparon a los funcionarios municipales que realizaban visitas de campaña, y quienes participaron en la campaña electoral culparon a quienes se reunieron para celebrar gillatunes.

\section{Salida: Experiencias de futuros posibles}

En cada devastación subyace una intencionalidad. Con ello, la acción de devastar para que otros habiten y, coincidentemente, impedir su autonomía, pareciera ser un común denominador en su dimensión territorial. Las cajas de alimentos entregadas por el gobierno a familias vulnerables cumplen este rol al surgir como respuesta inmediata del gobierno por la emergencia de ollas comunes en sectores de más bajos recursos. A las experiencias de futuros posibles lo antecede la crisis (krisis, decidir), lo que da cuenta de este conjunto de decisiones, en diversas escalas y escenarios, que transforman los contextos socioambientales a escala comunitaria, local e inclusive global.

La experiencia (ensayar) de una devastación dimensiona lo vivido y se representa en las prácticas culturales y cotidianas que se desenvuelven en contextos devastados. La sobrevivencia, el trauma y las acciones individuales y colectivas son claves en ello. Como ensayo, las barreras sanitarias mapuche son parte del proceso de autodeterminación territorial que acontece en Wallmapu. En este ensayo se incluyen múltiples posibilidades para sortear el problema, hundirse más (en cuanto a ruina). La escala socioecológica (TOLEDO, 2019) de la experiencia permite contextualizarla en lo que definimos como Coronaceno, esta situación de pandemia global que puede resultar expedita y con traumas profundos en las personas. Pero, la noción de "territorios descansando" de la

Caderno Eletrônico de Ciências Sociais, Vitória, v. 8, n. 2, pp. 70-83, 2020. 
acción humana resulta interesante de abordar en la experiencia. Flora y fauna reaparecen en territorios urbanizados y/o devastados por acciones humanas. 0 más bien, ante la ausencia de prácticas humanas, otras especies emergen espacios y generan una sensación de descanso. Este es el caso del liquen en los árboles del camino al paso fronterizo Mamuil Malal en Curarrehue. Ante el cierre de CONAF, en palabras de sus guardaparques reapareció liquen en los árboles a borde de camino como un síntoma de no-acción humana. Otro ejemplo es la "bajada" de animales silvestres desde las montañas hacia ciudades en tiempos de cuarentena y menor tránsito humano.

¿Qué acontecimientos proceden a la devastación?, la pregunta por el devenir (devenire, llegar a ser) trasciende a su sentido metafórico de lo divino y se orienta hacia posicionamientos a futuros posibles. Más allá de la pregunta sobre los pluriversos (ESCOBAR, 2018), en una visión poco optimista nos obliga a hacerlo lugarizado y localizado. La regeneración de la vida, como la oportunidad de reconocer a quienes su contribución al futuro no ha sido considerada (SKEWES, 2019) es una oportunidad para preguntarnos y abrir espacios a los futuros posibles. ¿Cuáles son los ritmos cotidianos que se sociabilizarán?, ¿cuál(es) es el habitus que se instalará?, ¿cuáles son las micropolíticas que trascenderán al acontecimiento del Coronaceno?, son preguntas que se abren con el devenir. Con los meses se institucionalizaron las ollas comunes por parte de fundaciones y no es solamente un hecho motivado en el momento por un grupo de personas es constatación de esta trascendencia.

\section{Conclusión}

Estamos viviendo el Coronaceno y solamente podemos especular por su fecha de origen (sería el 31 de diciembre de 2019 por un consumo conspicuo de Pangolín en un mercado de Wuhan, China) pero no de su fin. Vivimos la incertidumbre, el trauma, el cansancio y la calamidad de una pandemia en el siglo XXI. Es una tempestad generalizada, en cuanto a detener el motor y esperar que acabe, quedando en manos de otros. Ahora, cuando estos otros devastan para sostener modelos de desarrollo emergen los acontecimientos territoriales. Ollas comunes y barreras sanitarias mapuche sirven de situaciones ejemplares para dar cuenta del argumento central. $Y$, desde una mirada optimista, en posibilidades para regenerar la vida durante y posteriormente al Coronaceno. Los tejidos comunitarios se están restituyendo, en que a las ollas comunes lo acompañan nuevos huertos urbanos y familiares; a las barreras sanitarias mapuche lo acompañan imaginarios de soberanía territorial. Es así como reflexionar sobre la devastación como un acontecimiento territorial abre líneas por profundizar en futuras pesquisas que permitan dar una comprensión

Caderno Eletrônico de Ciências Sociais, Vitória, v. 8, n. 2, pp. 70-83, 2021. 
global e interdisciplinar sobre los futuros posibles desde la mirada de la devastación.

\section{Referencias bibliográficas}

ABALERON, C. 2010. De la Tragedia de los Comunes a lo común de las tragedias. Lider, 12(17), pp. 37-52.

ALIAGA, F. Y E. CARRETERO. 2016. El abordaje sociológico de los imaginarios sociales en los últimos veinte años. Espacio abierto. Cuaderno Venezolano de Sociología.

ALVAREZ, R., AZÓCAR, F., MARIHUAN, G., MONTERO, A., \& ROSENBLUTH, M. 2019. Turismo indígena como respuesta a la siniestralidad: Comunidad Mapuche-Lafkenche del lago Budi, Chile. REDER, 3(1), pp. 24-40.

ANGUS, I. 2016. Facing the Anthropocene: fossil capitalism and the crisis of the earth system. NYU Press.

ARAOS, F., JC SKEWES, W. RIQUELME. En prensa. La emergencia del Coronaceno:

la supervivencia en tiempos de pandemia. Revista Lider.

ARAOS, F., W. RIQUELME, JC SKEWES, A. VIANNA, R. ÁLVAREZ, F. THER, A. YU IWAMA, S. ALBAGLI, A. COSTA Y E. DUARTE. 2019. La vida después de la devastación: lo común de la tragedia en territorios sociobiodiversos de Chile y Brasil. Revista Antropologías del Sur, 6(12), pp. 87-106.

BALANDIER, G. 2003. El desorden. La teoría del caos y las ciencias sociales. Gedisa.

BONILLA-ALDANA, K., VILLAMIL-GÓMEZ, W., RABAAN, A., RODRÍGUEZ-MORALES, A. 2020. Una nueva zoonosis viral de preocupación viral: COVID-19, enfermedad por coronavirus 2019. Iatreia, 33(2), pp. 107-110.

CASTORIADIS, C. 2005. Los dominios del hombre. Las encrucijadas del laberinto. Barcelona: Gedisa.

CRUTZEN, P. J., \& STOERMER, E. F. 2000. The Anthropocene. Global Change Newsletter, 41, pp. 17-18.

ESCOBAR, A. 2018. Designs for the Pluriverse Radical Interdependence, Autonomy, and the Making of Worlds. Durham, North Carolina: Duke University Press.

FLEMING, P. 2017. The Death of Homo Economicus: Work, Debt and the Myth of Endless Accumulation. Londres: Pluto Press.

HARAWAY, D., ISHIKAWA, N., GILBERT, S. F., OLWIG, K., TSING, A. L., \& BUBANDT, N. 2016. Anthropologists Are Talking - About the Anthropocene. Ethnos, 81(3), pp. 535-564. https://doi.org/10.1080/00141844.2015.1105838

HARAWAY, D. J. 2016. Staying with the trouble: Making kin in the Chthulucene. Duke University Press.

Caderno Eletrônico de Ciências Sociais, Vitória, v. 8, n. 2, pp. 70-83, 2020. 
HARDIN, G. 1968. The Tragedy of the Commons. Science, 162(3859), pp. 12431248. doi: https://doi.org/10.1126/science.162.3859.1243

LEFF, E. 2019. Devenir de la vida y trascendencia histórica: las vías abiertas del diálogo de saberes. Desenvolv. Meio Ambiente, 50: 4.20.

MARIMÁN, J. 2012. Autodeterminación. Ideas políticas mapuche en el albor del siglo XXI. Santiago: LOM Ediciones.

SKEWES, J., F. ARAOS Y W. RIQUELME. 2020. Las desventuras del coronaceno. Entre el pangolin y el witranalwe. Raza Cómica. Disponible en: https://razacomica.cl/sitio/2020/07/04/las-desventuras-del-coronaceno-entreel-pangolin-y-el-witranalwe/

SKEWES, JC. 2019. La regeneración de la vida en los tiempos del capitalismo. Otras huellas en los bosques nativos del centro y sur de Chile. Santiago: Ocho Libros Editores.

TANG, X., WU, C., LI, X., SONG, Y., YAO, X., WU X., DUAN, Y. ZHANG, H., WANG, Y., QIAN, Z., CUI, J., LU. J. 2020. On the origin and continuing evolution of SARS-CoV-2. National Science Review, 7, pp. 1012-1023.

THER, F. 2012. Antropología del territorio. Polis, 11(32), pp. 493-510.

TSING, A., SWANSON, H., GAN, E. \& BUBANDT, N. 2017. The Arts of Living on a Damaged Planet. Minneapolis: University of Minnesota Press.

TSING, A. 2015. The Mushroom at the End of the World: On the Possibility of Life in Capitalist Ruins. New Jersey: Princeton University Press.

WEISMAN, A. 2007. The World Without Us. Nueva York: Thomas Dunne Books/St. Martin's Press. 